\title{
Estimating components of covariance between two climate variables using model ensembles
}

\author{
S. Grainger ${ }^{1} \quad$ C. S. Frederiksen ${ }^{2} \quad$ X. Zheng ${ }^{3}$
}

(Received 27 January 2011; revised 24 June 2011)

\begin{abstract}
The seasonal mean of a climate variable is considered to consist of: (a) slow-external; (b) slow-internal; and (c) intraseasonal components. Using an Analysis of Variance-based method, the interannual variability of the seasonal mean from an ensemble of coupled atmosphere-ocean general circulation model realisations is separable into these components. Here, we propose a method for analysing the covariability of these components between pairs of climate variables. In particular, the method allows for an estimate of the covariability of the projected time series of the modes of variability of one climate variable with the time series of another. To illustrate this, the relationship between time series of the modes of variability of $500 \mathrm{hPa}$ geopotential height and sea surface temperature is examined for an ensemble of coupled general circulation model realisations. The method is applicable to other atmospheric climate variables and datasets.
\end{abstract}

http://anziamj.austms.org.au/ojs/index.php/ANZIAMJ/article/view/3928 gives this article, (c) Austral. Mathematical Soc. 2011. Published July 5, 2011. ISSN 1446-8735. (Print two pages per sheet of paper.) Copies of this article must not be made otherwise available on the internet; instead link directly to this URL for this article. 


\section{Contents}

1 Introduction

C319

2 Methodology

C320

3 Example

C324

4 Conclusions

C329

References

C330

\section{Introduction}

The variability of the atmospheric circulation is controlled by many physical processes, which may act on time scales ranging from days to years. These processes, on these different timescales, can influence the interannual variability of the seasonal mean of a climate variable [1]. Consequently, a seasonal mean climate anomaly is considered as a statistical random variable consisting of signal and noise components [2]. The signal is related to slowly varying (a season or longer) processes and is considered as the slow component of interannual variability of the seasonal mean [3]. For an ensemble of model realisations, Zheng and Frederiksen [4] showed that the slow component is further separable into two components; one externally forced (slow-external) and one related to slowly varying internal sources (slow-internal). The noise is related to internal dynamics with intraseasonal time scales of about 1490 days. This has been referred to as the intraseasonal component of the seasonal mean [3].

Zheng and Frederiksen [3] formulated a method for estimating the statistical modes of interannual covariability of the slow and intraseasonal components. Using monthly mean data, the interannual covariability of the seasonal mean is estimated by second moments. Note that this approach differs from time 
filtering of daily data, which has been used to identify variability within frequency bands (for example, 30-60 days for intraseasonal variability). For interannual covariability of the seasonal mean, a seasonal mean operator is applied to separate the signal and noise components, and the result will be essentially the same as using raw daily data, filtered or unfiltered [5].

Frederiksen and Zheng [6] applied the method of Zheng and Frederiksen [3] to the Southern Hemisphere $500 \mathrm{hPa}$ geopotential height field in reanalysis data. How well coupled atmosphere-ocean general circulation models (CGCMs) are able to reproduce these modes has been assessed [7]. However, in order to understand the external forcings or internal sources related to modes of variability of the slow component in CGCMs, it is useful to investigate the relationship between the time series of the modes and other climate variables such as sea surface temperature (SST). Here, we extend the estimation of the variability of components for an ensemble of realisations formulated by Zheng et al. [8] to the case of coupled covariance between the time series associated with a mode of variability, and another climate variable. To illustrate the method, we investigate the sources of atmospheric variability related to the El Nino-Southern Oscillation (ENSO) in the current and a projected future climate.

\section{Methodology}

Given the conceptual model described in section 1, the separation into the three components is possible given at least monthly data $[1,8]$. Here, we assume that we have monthly mean data on a spatial grid for an ensemble of model realisations. In that case, the monthly mean anomaly, after the annual cycle has been removed, of a climate variable $x$ at any grid point is represented as [8]

$$
x_{\text {sym }}=\beta_{y}+\delta_{s y}+\varepsilon_{s y m},
$$

where $s=1, \ldots, S$ is the realisation number in an ensemble of size $S, y=$ $1, \ldots, Y$ is the year index in a sample of $Y$ years and $m=1,2,3$ is the month 
index in the season. The slow-external component, independent of realisation, is $\beta_{y}, \delta_{s y}$ is the slow-internal component, taken to be constant over a season, and the residual monthly departure of $x_{\text {sym }}$ from the slow components, $\varepsilon_{\text {sym }}$, is the intraseasonal component.

Grainger et al. [9] showed that for the model given by equation (1), it is possible to estimate covariance matrices for the components of the interannual variability of the seasonal mean. The modes of interannual variability of each component are defined to be the Empirical Orthogonal Functions (EOFs) obtained by eigenvalue decomposition [10] of the corresponding covariance matrix, in descending order by variance explained. For any EOF, the associated time series, denoted here by $p_{\text {sym }}^{t}$, is calculated by projecting the monthly anomalies $x_{\text {sym }}$ at all grid points onto the EOF. The associated time series, also referred to here as a Principal Component (PC) time series, is also separable into components, that is,

$$
p_{s y m}^{t}=\beta_{y}^{t}+\delta_{s y}^{t}+\varepsilon_{s y m}^{t} .
$$

Suppose that there is a second spatially gridded climate variable $x_{\text {sym }}^{\prime}$ that is also separable into components. That is, at any grid point,

$$
x_{s y m}^{\prime}=\beta_{y}^{\prime}+\delta_{s y}^{\prime}+\varepsilon_{s y m}^{\prime} .
$$

Then it is possible to estimate the interannual covariability of the components of the times series $p_{\text {sym }}^{t}$ and $x_{\text {sym }}^{\prime}$. Firstly,

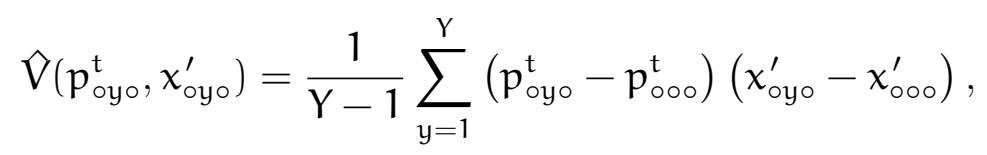

is the covariance of the ensemble mean seasonal means, where a subscript $\circ$ represents an average over an index $(s, y$ or $m)$, and $\widehat{\nabla}$ denotes the estimated covariance. Next,

$$
\widehat{\nabla}\left(\delta_{\text {sy }}^{\mathrm{t}}+\varepsilon_{\text {syo }}^{\mathrm{t}}-\delta_{\text {oy }}^{\mathrm{t}}-\varepsilon_{\text {oyo }}^{\mathrm{t}}, \delta_{\text {sy }}^{\prime}+\varepsilon_{\text {syo }}^{\prime}-\delta_{\text {oy }}^{\prime}-\varepsilon_{\text {oyo }}^{\prime}\right)
$$




$$
=\frac{1}{Y(S-1)} \sum_{y=1}^{Y} \sum_{s=1}^{S}\left(p_{\text {syo }}^{t}-p_{\text {oyo }}^{t}\right)\left(x_{\text {syo }}^{\prime}-x_{\text {oy。 }}^{\prime}\right),
$$

is the covariance of the internal components. Also, Zheng et al. [8] showed that the covariance of the intraseasonal components is able to be estimated as a function of monthly moments. In this case,

$$
\widehat{\nabla}\left(\varepsilon_{\text {syo }}^{\mathrm{t}}, \varepsilon_{\text {syo }}^{\prime}\right)=\frac{1}{9}[\hat{\alpha}(3+4 \hat{\phi})],
$$

where

$$
\hat{\alpha}=\frac{a}{2(1-\hat{\phi})}
$$

is the covariance of the intraseasonal components within each month, and

$$
\hat{\phi}=\frac{a+2 b}{2(a+b)}, \quad 0 \leqslant \hat{\phi} \leqslant 0.1,
$$

is the intermonthly correlation between consecutive months. The covariance and intermonth correlations of the intraseasonal components are assumed to be independent of months within a season. The monthly moments $a$ and $b$ are defined as

$$
\begin{aligned}
a=\frac{1}{2} & {\left[\frac{1}{Y S} \sum_{y=1}^{Y} \sum_{s=1}^{S}\left(p_{s y 1}^{t}-p_{s y 2}^{t}\right)\left(x_{s y 1}^{\prime}-x_{s y 2}^{\prime}\right)\right.} \\
& \left.+\frac{1}{Y S} \sum_{y=1}^{Y} \sum_{s=1}^{S}\left(p_{s y 2}^{t}-p_{s y 3}^{t}\right)\left(x_{s y 2}^{\prime}-x_{s y 3}^{\prime}\right)\right], \\
b= & \frac{1}{2}\left[\frac{1}{Y S} \sum_{y=1}^{Y} \sum_{s=1}^{S}\left(p_{s y 1}^{t}-p_{s y 2}^{t}\right)\left(x_{s y 2}^{\prime}-x_{s y 3}^{\prime}\right)\right. \\
& \left.+\frac{1}{Y S} \sum_{y=1}^{Y} \sum_{s=1}^{S}\left(p_{s y 2}^{t}-p_{s y 3}^{t}\right)\left(x_{s y 1}^{\prime}-x_{s y 2}^{\prime}\right)\right] .
\end{aligned}
$$


From equations (4), (5) and (6) the interannual covariances of the remaining components are estimated. Using equation (5), the covariance of the total internal components is estimated by

$\widehat{\nabla}\left(\delta_{s y}^{t}+\varepsilon_{s y o}^{t}, \delta_{s y}^{\prime}+\varepsilon_{s y o}^{\prime}\right)=\frac{S}{S-1} \widehat{\nabla}\left(\delta_{s y}^{t}+\varepsilon_{s y o}^{t}-\delta_{o y}^{t}-\varepsilon_{o y o}^{t}, \delta_{s y}^{\prime}+\varepsilon_{s y o}^{\prime}-\delta_{o y}^{\prime}-\varepsilon_{o y o}^{\prime}\right)$.

The covariance of the slow-external components is estimated from equations (4) and (11) by

$$
\begin{aligned}
\widehat{\nabla}\left(\beta_{y}^{\mathrm{t}}, \beta_{y}^{\prime}\right)= & \widehat{\nabla}\left(\mathrm{p}_{\text {oyo }}^{\mathrm{t}}, x_{\text {oyo }}^{\prime}\right)-\frac{1}{\mathrm{~S}} \widehat{\nabla}\left(\delta_{\text {sy }}^{\mathrm{t}}+\varepsilon_{\text {syo }}^{\mathrm{t}}, \delta_{\text {sy }}^{\prime}+\varepsilon_{\text {syo }}^{\prime}\right) \\
= & \widehat{\nabla}\left(\mathrm{p}_{\text {oyo }}^{\mathrm{t}}, x_{\text {oyo }}^{\prime}\right) \\
& -\frac{1}{S-1} \widehat{\nabla}\left(\delta_{\text {sy }}^{\mathrm{t}}+\varepsilon_{\text {syo }}^{\mathrm{t}}-\delta_{\text {oy }}^{\mathrm{t}}-\varepsilon_{\text {oyo }}^{\mathrm{t}}, \delta_{\text {sy }}^{\prime}+\varepsilon_{\text {syo }}^{\prime}-\delta_{\text {oy }}^{\prime}-\varepsilon_{\text {oyo }}^{\prime}\right) .
\end{aligned}
$$

Using equations (11) and (12), the covariance of the total seasonal mean components is then estimated by

$$
\begin{aligned}
\widehat{\nabla}\left(p_{\text {syo }}^{\mathrm{t}}, x_{\text {syo }}^{\prime}\right)= & \widehat{\nabla}\left(\beta_{y}^{\mathrm{t}}, \beta_{y}^{\prime}\right)+\widehat{\nabla}\left(\delta_{s y}^{\mathrm{t}}+\varepsilon_{\text {syo }}^{\mathrm{t}}, \delta_{\text {sy }}^{\prime}+\varepsilon_{\text {syo }}^{\prime}\right) \\
= & \widehat{\nabla}\left(p_{\text {oyo }}^{\mathrm{t}}, x_{\text {oyo }}^{\prime}\right)+\frac{S-1}{S} \widehat{\nabla}\left(\delta_{\text {sy }}^{\mathrm{t}}+\varepsilon_{\text {syo }}^{\mathrm{t}}, \delta_{s y}^{\prime}+\varepsilon_{\text {syo }}^{\prime}\right) \\
= & \widehat{\nabla}\left(p_{\text {oyo }}^{\mathrm{t}}, x_{\text {oyo }}^{\prime}\right) \\
& +\widehat{\nabla}\left(\delta_{\text {sy }}^{\mathrm{t}}+\varepsilon_{\text {syo }}^{\mathrm{t}}-\delta_{\text {oy }}^{\mathrm{t}}-\varepsilon_{\text {oyo }}^{\mathrm{t}}, \delta_{\text {sy }}^{\prime}+\varepsilon_{\text {syo }}^{\prime}-\delta_{\text {oy }}^{\prime}-\varepsilon_{\text {oyo }}^{\prime}\right) .
\end{aligned}
$$

Finally, the covariances of the slow-internal (slow) components are estimated as differences between the covariances of the total internal (total) and the intraseasonal components (equation 6), that is,

$$
\begin{aligned}
\widehat{\nabla}\left(\delta_{s y}^{t}, \delta_{s y}^{\prime}\right) & =\widehat{\nabla}\left(\delta_{s y}^{t}+\varepsilon_{s y o}^{t}, \delta_{s y}^{\prime}+\varepsilon_{s y o}^{\prime}\right)-\widehat{\nabla}\left(\varepsilon_{s y o}^{t}, \varepsilon_{s y o}^{\prime}\right) \\
\nabla\left(\beta_{y}^{t}+\delta_{s y}^{t}, \beta_{y}^{\prime}+\delta_{s y}^{\prime}\right) & =\widehat{\nabla}\left(p_{s y o}^{t}, x_{s y o}^{\prime}\right)-\nabla\left(\varepsilon_{s y o}^{t}, \varepsilon_{s y o}^{\prime}\right) .
\end{aligned}
$$

Thus, the covariances of all the components between $p_{\text {sym }}^{t}$ and $x_{\text {sym }}^{\prime}$ are estimated. This is repeated at all grid points of $x_{\text {sym }}^{\prime}$ for EOFs of the components 
of $x_{\text {sym }}$ that are of interest. In most cases, the covariances of the slow, slowinternal or slow-external components are the most relevant because they may be related to important sources of interannual variability such as SST or greenhouse gas forcing.

\section{Example}

To illustrate the methodology, the sources related to interannual variability of $500 \mathrm{hPa}$ geopotential height for the Southern Hemisphere summer (December, January and February) are investigated through the covariance with SST. CGCM data were obtained from the World Climate Research Program (WCRP) Coupled Model Intercomparison Project phase 3 (CMIP3) dataset [11]. As in Grainger et al. [7], data from the National Centers for Environmental Prediction (NCEP) National Center for Atmospheric Research reanalysis [12] for the period 1951-2000 is used as the reference dataset. Observed SST data were obtained from the HADISST dataset [13]. All $500 \mathrm{hPa}$ geopotential height data were mapped to a $2.5^{\circ} \times 2.5^{\circ}$ latitude/longitude grid, and SST data to a $2^{\circ} \times 2^{\circ}$ latitude/longitude grid. For the model $500 \mathrm{hPa}$ geopotential height, covariance matrices for the slow, slow-internal and slow-external components were estimated using the method of Grainger et al. [9]. Here, the corresponding modes of variability are referred to as the slow, slow-internal and slow-external EOFs, respectively.

For the NCEP reanalysis, the slow modes of variability were estimated using the method of Zheng and Frederiksen [3], and the covariance between the slow components of the PC time series of the height field and the SST time series (equation 15) using the method in section 2 with $S=1$. Figure 1a shows the slow EOF-2 of NCEP $500 \mathrm{hPa}$ geopotential height and the corresponding covariance with observed ssT. Frederiksen and Zheng [6] found that this mode is related to ENSO variability. This is seen in both the teleconnection pattern of the EOF loadings and the high positive covariance with tropical Pacific SST. 
(a)

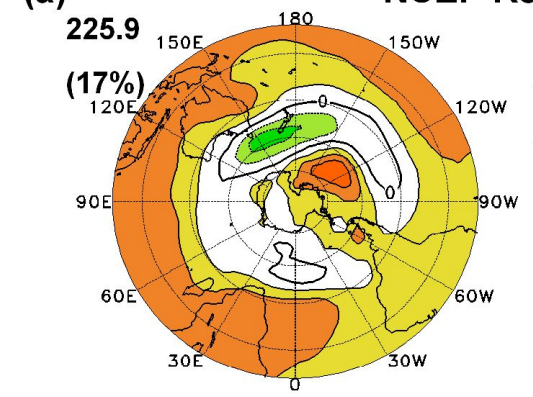

(b)
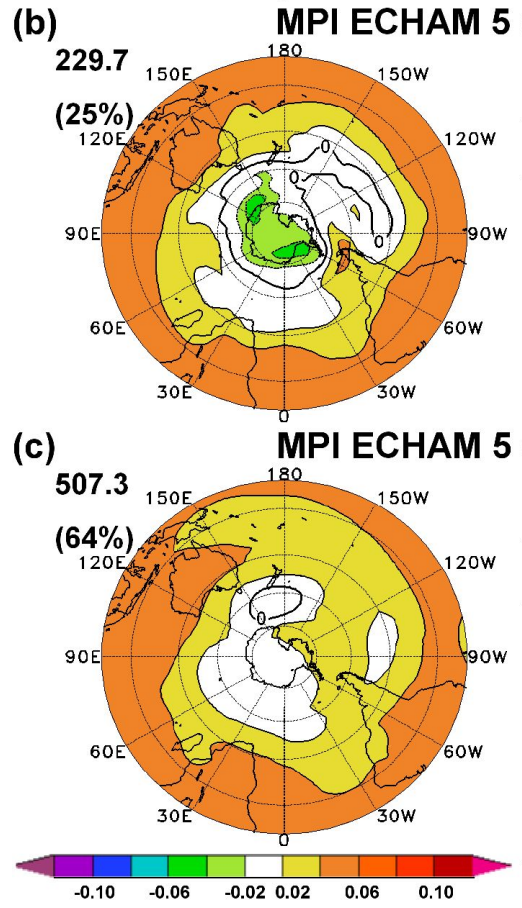

NCEP Reanalysis
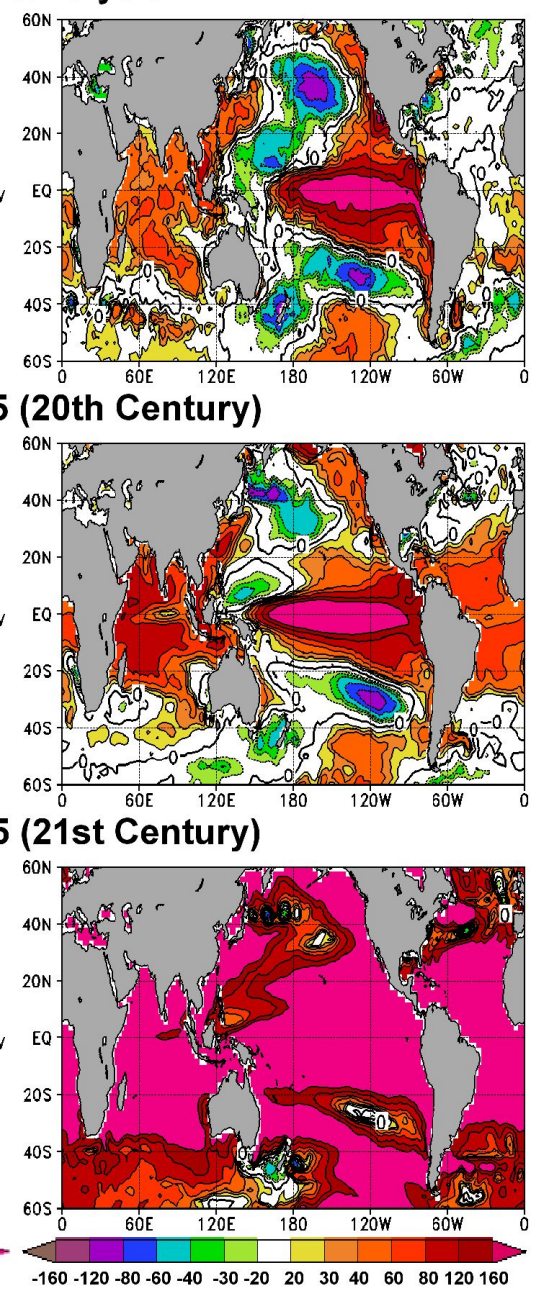

Figure 1: Slow EOF-2 of $500 \mathrm{hPa}$ geopotential height (left) and covariance with the slow component of SST (right) for (a) NCEP reanalysis, (b) MPI ECHAM 5 for the second half of the 20th century, and (c) MPI ECHAM 5 for the second half of the 21st century. The EOFs are normalised to unit length. The square root of the eigenvalue (units $\mathrm{m}$ ) and percentage explained of the slow covariance is given next to each EOF. 
(a)

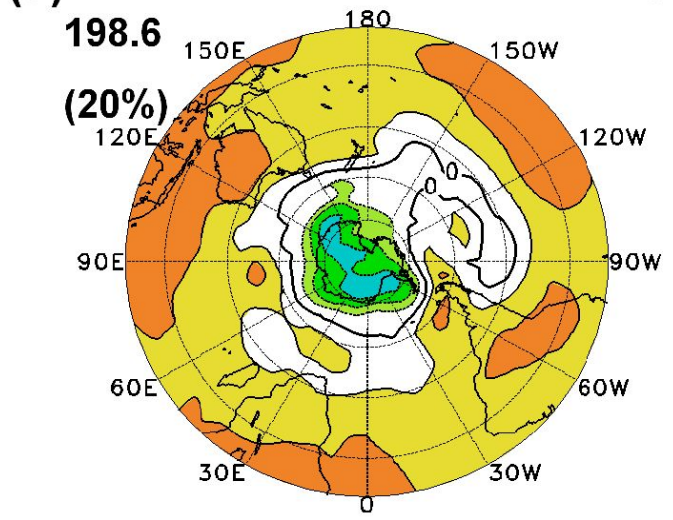

(b)

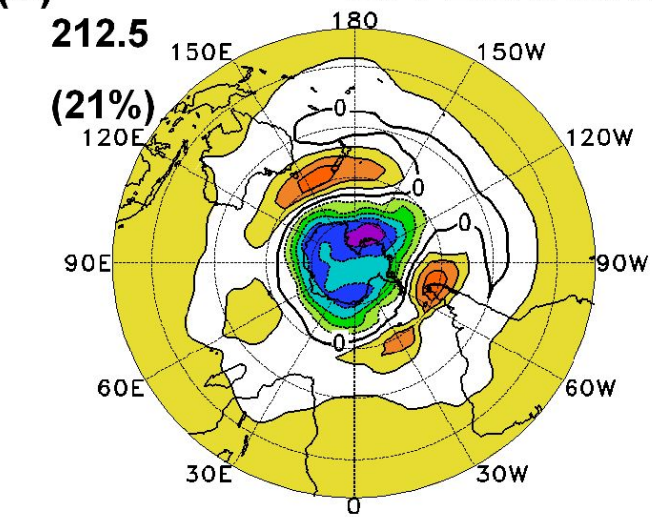

$\begin{array}{lllll}-0.10 & -0.06 & -0.02 & 0.02 & 0.06\end{array}$
MPI ECHAM 5 (20th Century)

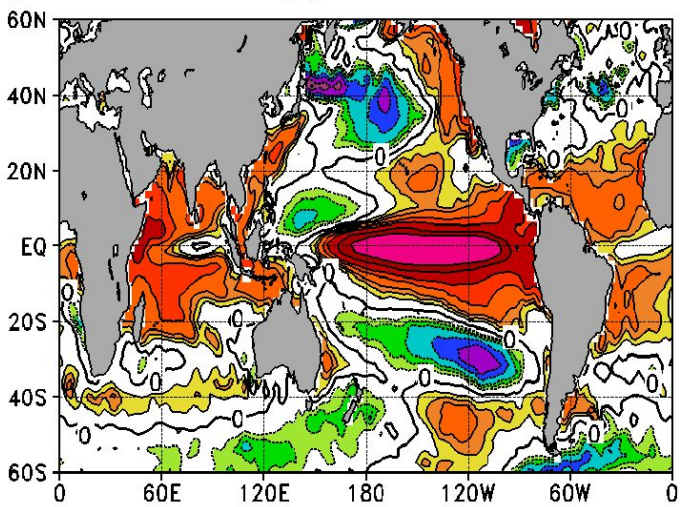

5 (21st Century)

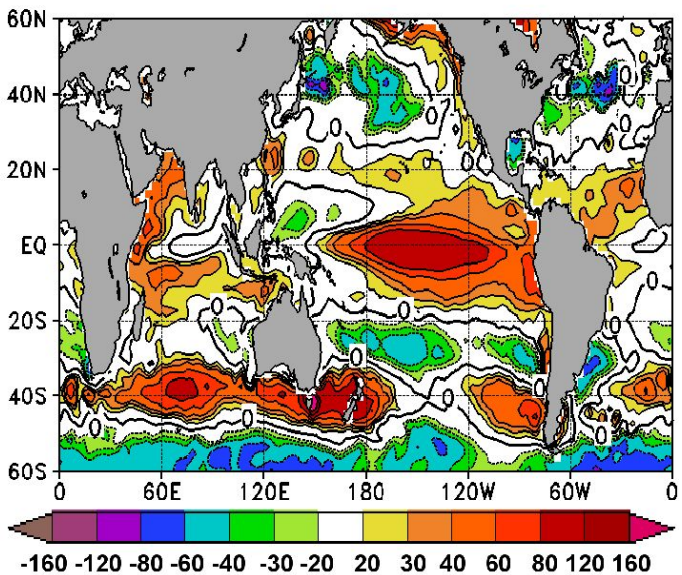

FIGURE 2: As in Figure 1 but for the slow-internal EOF-2 estimated by (a) MPI ECHAM 5 for the second half of the 20th century, and (b) MPI ECHAM 5 for the second half of the 21st century. 
Realisations from the 20c3m scenario [11] were taken to represent the second half of the 20th century in the CMIP3 models. A preliminary comparison with the NCEP reanalysis found that MPI ECHAM $5(\mathrm{~S}=4)$ was one of the best of the 23 CMIP3 models at reproducing the structure of the intraseasonal and slow EOFs. The slow EOF- 2 of $500 \mathrm{hPa}$ geopotential height and corresponding covariance with model SST for MPI ECHAM 5 is shown in Figure 1b. MPI ECHAM 5 reproduces well the structure and magnitude of the ENSO variability estimated by the NCEP reanalysis.

To investigate how ENSO variability might change under projected future climate, results for the second half of the 21st century were obtained for MPI ECHAM 5 realisations of the SRESA1B scenario [11], and are shown in Figure 1c. The equivalent mode is now the leading slow EOF for MPI ECHAM 5. The EOF loadings are more uniform, and there are large positive SST covariances almost everywhere.

The large change in slow ENSO mode in MPI ECHAM 5 is further investigated by separating the covariance of the slow component of $500 \mathrm{hPa}$ geopotential height into slow-internal and slow-external components. Figures 2 and 3 respectively show slow-internal EOF-2 and slow-external EOF-1 and their SST covariances (equations 14 and 12, respectively) from MPI ECHAM 5 for the 20 th and 21st centuries. The 20th century slow-internal EOF-2 (Figure 2a) is almost identical in structure to the slow EOF-2 (Figure 1b). There is little change in the 21st century slow-internal EOF-2 (Figure 2b) except for higher EOF loadings and positive SST covariance at high latitudes. The leading slow-external EOF in MPI ECHAM 5 in the 20th century (Figure 3a) has low variability (as indicated by the eigenvalue) and weak SST covariance. However, the structure of the EOF is similar to the greenhouse gas response found in CGCM forcing studies [14], suggesting that slow-external EOF-1 is related to the trend in greenhouse gas concentrations. In contrast, in the 21st century the slow-external EOF-1 (Figure 3b) has a uniform structure in the EOF loading, and very high positive SST covariances everywhere, similar to the slow EOF-1 (Figure 1c). However, slow EOF-1 has a higher eigenvalue than slow-external EOF-1, indicating that it still includes a slow-internal component. 
(a)

(b)
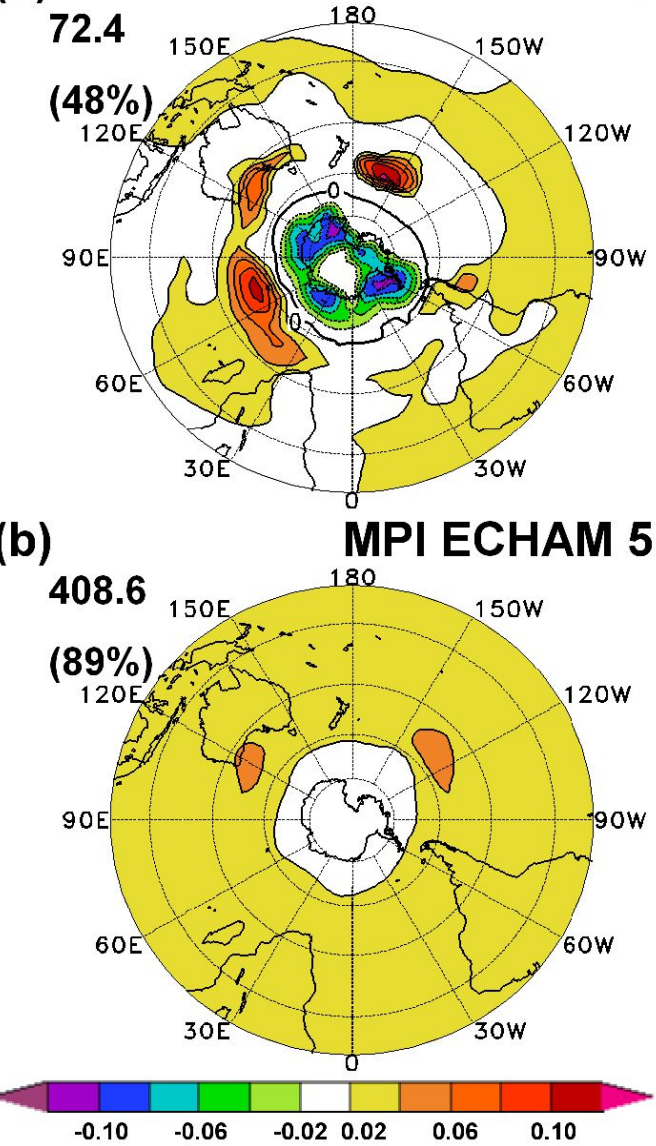

MPI ECHAM 5 (20th Century)

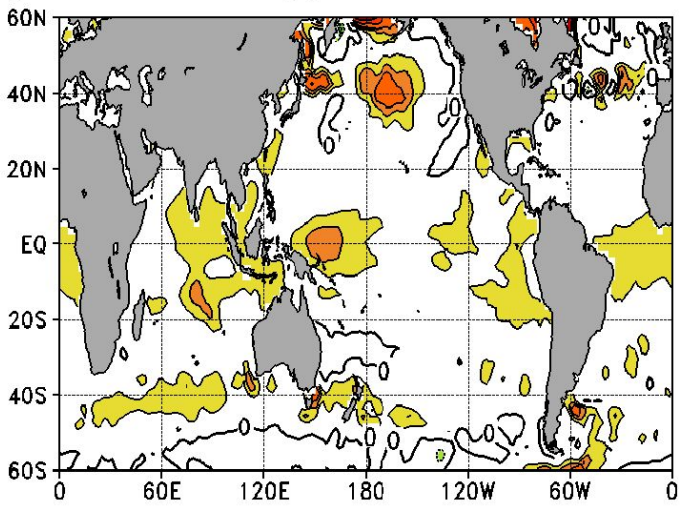

\section{(21st Century)}

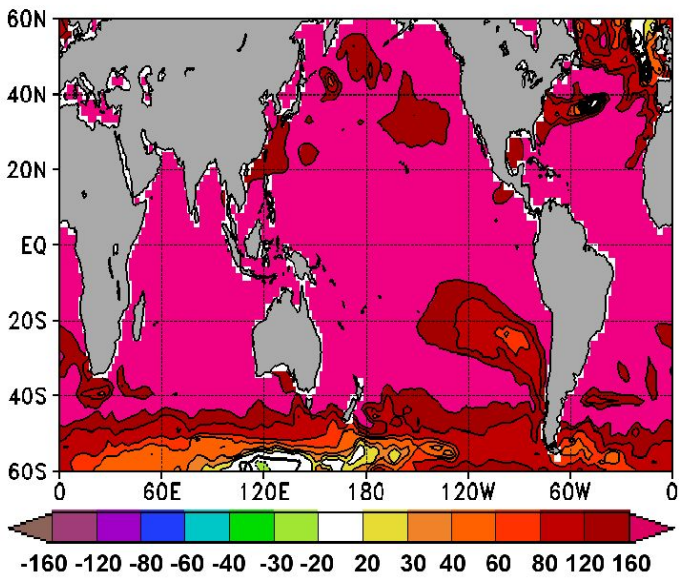

Figure 3: As in Figure 2, but for MPI ECHAM 5 slow-external EOF-1. 


\section{Conclusions}

We described how existing methods for estimating the interannual variability of components of the seasonal mean of a climate variable have been extended to estimate the coupled covariance between a PC time series and a second climate variable in an ensemble of CGCM realisations. In this way, the external forcings and internal sources of the slow modes of variability are investigated. As an example, we applied this method to the covariance between PC time series of EOFs of $500 \mathrm{hPa}$ geopotential height and SST in CGCMs from the WCRP CMIP3 dataset. To better understand changes in the slow modes of variability of $500 \mathrm{hPa}$ geopotential height in the 21st century, it was useful to separate the covariance of the slow component into slow-internal and slow-external components. There was little change in the slow-internal modes of variability between the 20th and 21st centuries, but large differences were found in the leading slow-external EOF. That is, for the model shown, the largest differences in the interannual variability of the seasonal mean geopotential height are due to the changes in the greenhouse gas forcing.

The method formulated in section 2 is applicable to many climate variables and datasets. In particular, it is extendable to time series of monthly anomalies of two spatially gridded climate variables, for example the geopotential height field and surface temperature.

Acknowledgements We acknowledge the modelling groups, the Program for Climate Model Diagnosis and Intercomparison and the WCRP's Working Group on Coupled Modelling for their roles in making available the CMIP3 multi-model dataset. S. Grainger is supported by the Australian Climate Change Science Program of the Australian Department of Climate Change and Energy Efficiency. X. Zheng is supported by 2010CB428402 National Program on Key Basic Research Project of China and 40975062/40875062 NSFC. 


\section{References}

[1] C. S. Frederiksen and X. Zheng. Coherent structures of interannual variability of the atmospheric circulation: the role of intraseasonal variability. Frontiers in Turbulence and Coherent Structures, World Scientific Lecture Notes in Complex Systems, Vol. 6, Eds Jim Denier and Jorgen Frederiksen, World Scientific Publications, 87-120, 2007. C319, C320

[2] C. E. Leith. The standard error of time-average estimates of climatic means. J. Appl. Meteor., 12:1066-1069, 1973. doi:10.1175/1520-0450(1973)012;1066:TSEOTA¿2.0.CO;2 C319

[3] X. Zheng and C. S. Frederiksen. Variability of seasonal-mean fields arising from intraseasonal variability. Part 1, methodology. Climate Dynamics, 23:177-191, 2004. doi:10.1007/s00382-004-0428-7 C319, C320, C324

[4] X. Zheng and C. S. Frederiksen. Validating interannual variability in an ensemble of AGCM simulations. J. Climate, 12:2386-2396, 1999. doi:10.1175/1520-0442(1999)012;2386:VIVIAE;2.0.CO;2 C319

[5] C. S. Frederiksen and X. Zheng. Variability of seasonal-mean fields arising from intraseasonal variability. part 2, application to nh winter circulations. Climate Dynamics, 23:193-206, 2004. doi:10.1007/s00382-004-0429-6 C320

[6] C. S. Frederiksen and X. Zheng. Variability of seasonal-mean fields arising from intraseasonal variability. Part 3: Application to SH winter and summer circulations. Climate Dynamics, 28:849-866, 2007. doi:10.1007/s00382-006-0214-9 C320, C324

[7] S. Grainger, C. S. Frederiksen and X. Zheng. A method for evaluating the modes of variability in general circulation models. ANZIAM J., 
50:C399-C412, 2008. http://anziamj . austms .org.au/ojs/index. php/ANZIAMJ/article/view/1431 C320, C324

[8] X. Zheng, M. Sugi and C. S. Frederiksen. Interannual variability and predictability in an ensemble of climate simulations with the MRI-JMA AGCM. J. Meteor. Soc. Jap., 82:1-18, 2004. doi:10.2151/jmsj.82.1 C320, C322

[9] S. Grainger, C. S. Frederiksen, X. Zheng, D. Fereday, C. K. Folland, E. K. Jin, J. L. Kinter, J. R. Knight, S. Schubert and J. Syktus. Modes of variability of Southern Hemisphere atmospheric circulation estimated by AGCMs. Climate Dynamics, 36:473-490, 2011.

doi:10.1007/s00382-009-0720-7 C321, C324

[10] H. von Storch and F. W. Zwiers. Statistical Analysis in Climate Research. Cambridge University Press, 484pp, 1999. C321

[11] G. A. Meehl, C. Covey, T. Delworth, M. Latif, B. McAvaney, J. F. B. Mitchell, R. J. Stouffer and K. E. Taylor. The WCRP CMIP3 multimodel dataset: A new era in climate change research. Bull. Amer. Meteor. Soc., 88:1383-1394, 2007. doi:10.1175/BAMS-88-9-1383 C324, C327

[12] E. Kalnay, M. Kanamitsu, R. Kistler, W. Collins, D. Deaven, L. Gandin, M. Iredell, S. Saha, G. White, J. Woollen, Y. Zhu, A. Leetmaa, R. Reynolds, M. Chelliah, W. Ebisuzaki, W. Higgins, J. Janowiak, K. C. Mo, C. Ropelewski, J. Wang, R. Jenne and D. Joseph. The NCEP/NCAR 40-year reanalysis project. Bull. Amer. Meteor. Soc., $77: 437-471,1996$. doi:10.1175/1520-0477(1996)077;0437:TNYRP ¿2.0.CO;2 C324

[13] N. A. Rayner, D. E. Parker, E. B. Horton, C. K. Folland, L. V. Alexander, D. P. Rowell, E. C. Kent and A. Kaplan. Global analyses of sea surface temperature, sea ice, and night marine air temperature since the late nineteenth century. J. Geophys. Res., 108(D14):4407, 2003. doi:10.1029/2002JD002670 C324 
[14] J. M. Arblaster and G. A. Meehl. Contributions of external forcings to Southern Annular Mode trends. J. Climate, 19:2896-2905, 2006. doi:10.1175/JCLI3774.1 C327

\section{Author addresses}

1. S. Grainger, Centre for Australian Weather and Climate Research, Bureau of Meteorology, Melbourne, Victoria 3001, Australia. mailto:s.grainger@bom.gov . au

2. C. S. Frederiksen, Centre for Australian Weather and Climate Research, Bureau of Meteorology, Melbourne, Victoria 3001, Australia.

3. X. Zheng, College of Global Change and Earth System Science, Beijing Normal University, Beijing, China. 